\title{
TBL1XR1-JAK2: a novel fusion in a pediatric T cell acute lymphoblastic leukemia patient with increased absolute eosinophil count
}

\author{
Xiaoyan Huang ${ }^{1} \cdot$ Mahmut Celiker $^{2} \cdot$ Ludovico Guarini $^{2} \cdot$ Smita Patel $^{3} \cdot$ Ning Neil Chen $^{1,3}$ (1)
}

Received: 11 May 2020 / Accepted: 23 August 2020 / Published online: 1 September 2020

(C) Springer-Verlag GmbH Germany, part of Springer Nature 2020

\begin{abstract}
T-lymphoblastic leukemia/lymphoma (T-ALL/LBL) with any JAK2 gene fusion is rarely reported. Here, we report a case of TALL with a novel TBL1XR1-JAK2 gene fusion in a 5-year-old boy. His lab showed a high white blood cell count, mild anemia, moderate thrombocytopenia, and concurrently increased eosinophils (absolute eosinophil count: $4 \times 10^{\wedge} 9 / \mathrm{L}$ ). Peripheral blood and bone marrow aspirate smears showed $>90 \%$ mononucleated blasts. Flow cytometry on peripheral blood revealed a large blast population positive for CD2, surface CD3 (<25\%), CD10 (50\%), CD5, CD7, CD4, CD8, TdT, CD1a (60\%), and CD45. Conventional karyotype analysis showed $\mathrm{t}(3 ; 9)(\mathrm{q} 26 ; \mathrm{p} 24)$ and $\mathrm{t}(11 ; 14)(\mathrm{p} 13 ; \mathrm{q} 11.2) / T C R D-L M O 2$. Next-generation sequencing (NGS) identified a novel TBL1XR1-JAK2 gene fusion in a sequencing depth of $180 \times$ by RNAseq, FBXW7 R465H mutation, and loss of exons 2-3 of $C D K N 2 A / B$ by DNAseq. Follow-up bone marrow aspirate on day-28 post-induction therapy revealed no morphologic evidence of residual leukemia. We believe that the TBL1XR1-JAK2 fusion may behave in a similar functional manner to the PCM1-JAK2 fusion gene and constitutes a new variant of this family and a potential target of tyrosine kinase inhibitor (TKI) therapy.
\end{abstract}

Keywords T-ALL/LBL $\cdot$ TBL1XR1-JAK2 gene fusion · Tyrosine kinase inhibitor

\section{Introduction}

$\mathrm{T}$ cell acute lymphoblastic leukemia/lymphoma (T-ALL/ $\mathrm{LBL}$ ) is an aggressive malignancy of early $\mathrm{T}$ cell progenitors, involving bone marrow and blood (T-ALL) or presenting with primary involvement in the thymus, lymph node, or extranodal site (T-LBL). It accounts for about $10-15 \%$ pediatric ALL cases with a predominance in male adolescents [1]. T-ALL/LBL in childhood is generally considered a higherrisk disease for presenting with high-risk features at diagnosis, such as older age and higher white blood cell count [2].

Ning Neil Chen

Neil.Chen@downstate.edu

1 Department of Pathology, SUNY Downstate Health Sciences University, Brooklyn, NY 11203, USA

2 Department of Pediatric Hematology and Oncology, Maimonides Medical Center, Brooklyn, NY 11219, USA

3 Department of Pathology, Maimonides Medical Center, Brooklyn, NY 11219, USA
Common genomic alterations in T-ALL/LBL include the activating mutation of the NOTCH1 signaling pathway, inactivating mutation of $F B X W 7$ signaling, and deletion or methylation of $C D K N 2 A$ and $C D K N 2 B$ [3]. Constitutional activation of $J A K-S T A T$ results from an activating mutation of JAK1 and JAK3 and is found in $10 \%$ of T-ALL/LBL patients [3].

JAK2 gene fusions have been reported in pediatric TALL/LBL cases (see Table 1). To date, more than thirty $J A K 2$ fusion variants affecting TEL(ETV6), PCM1, TPM3, CD99, MYH9, BCR, SSBP2, STRN3, PAX5, and others have been described [9]. Among these variants, the WHO 2016 proposed a provisional entity, specifically myeloid/ lymphoid neoplasms with PCM1-JAK2 in myeloid/ lymphoid neoplasms with eosinophilia and rearrangement of certain fusion genes category $[10,11]$. The diseases in this category can present in different ways, as myeloproliferative neoplasms (MPN), myelodysplastic/ myeloproliferative neoplasm (MDS/MPN), or lymphoid, as in our case. In this article, we present the TBL1XR1 gene as a novel $J A K 2$ fusion partner gene in a pediatric patient with T-ALL/LBL. 
Table 1 Literature study of JAK2 fusion partner genes in T-ALL/ LBL

\begin{tabular}{lllll}
\hline Fusion gene & Chromosomal translocation & Journal & Year & Reference \\
\hline TEL $($ ETV6) & $\mathrm{t}(9 ; 12)(\mathrm{p} 24 ; \mathrm{p} 13)$ & Science & 1997 & Lacronique et al. [4] \\
PCM1 & $\mathrm{t}(8 ; 9)(\mathrm{p} 22 ; \mathrm{p} 24)$ & Leukemia & 2006 & Adelaide J. et al. [5] \\
TPM3 & N/A & PLOS Genetics & 2013 & Atak ZK. et al. [6] \\
PCM1 & N/A & Nat Genet & 2017 & Liu Y. et al. [7] \\
CD99 & N/A & Nat Genet & 2017 & Liu Y. et al. [7] \\
MYH9 & N/A & PNAS & 2018 & Chen B. et al. [8] \\
\hline
\end{tabular}

\section{Clinical history}

The patient is a 5-year-old boy, with an unremarkable past medical history, who presented with new onset of a neck mass for 3 or 4 days, decreased appetite, abdominal pain, and mild fever (99.9 degrees F) for 1 day. His laboratory evaluation revealed mild anemia (hemoglobin $9.3 \mathrm{~g} / \mathrm{dL}$ ), high white blood cell count $\left(404.3 \times 10^{\wedge} 9 / \mathrm{L}\right)$, increased eosinophils (absolute eosinophil count: $\left.4 \times 10^{\wedge} 9 / \mathrm{L}\right)$, moderate thrombocytopenia (platelet count $66 \times 10^{\wedge} 11 / \mathrm{L}$ ), and high LDH (4800 units/L). Ultrasonographic study of the neck mass suggested it was composed of multiple enlarged lymph nodes. Peripheral blood and bone marrow aspirate smears showed $>90 \%$ mononucleated blasts with variably sized immature nuclei (see Fig. 1A and B).
Flow cytometry of peripheral blood revealed a large blast population positive for $\mathrm{CD} 2$, surface $\mathrm{CD} 3(<25 \%), \mathrm{CD} 10$ (50\%), CD5, CD7, CD4, CD8, TdT, CD1a (60\%), and CD45 and negative for CD34, CD117, CD13, CD33, CD14, CD64, CD11b, CD11c, HLD-DR, CD19, and CD20 (see Fig. $1 \mathrm{C}$ and D). By immunohistochemistry, blasts were negative for MPO on the bone marrow clot section. This immunophenotypic profile is a characteristic of $\mathrm{T}$ cell acute lymphoblastic leukemia/lymphoma (T-ALL/LBL).

Conventional karyotype analysis showed male karyotype $(46, X Y)$ and translocations $t(3 ; 9)(q 26 ; p 24)$ and $\mathrm{t}(11 ; 14)(\mathrm{p} 13 ; \mathrm{q} 11.2) / T C R D-L M O 2$ in 7 of 20 metaphase cells examined (see Fig. 2). The FISH analysis showed deletion of the CDKN2A gene on the short arm of chromosome 9 at $\mathrm{p} 21$
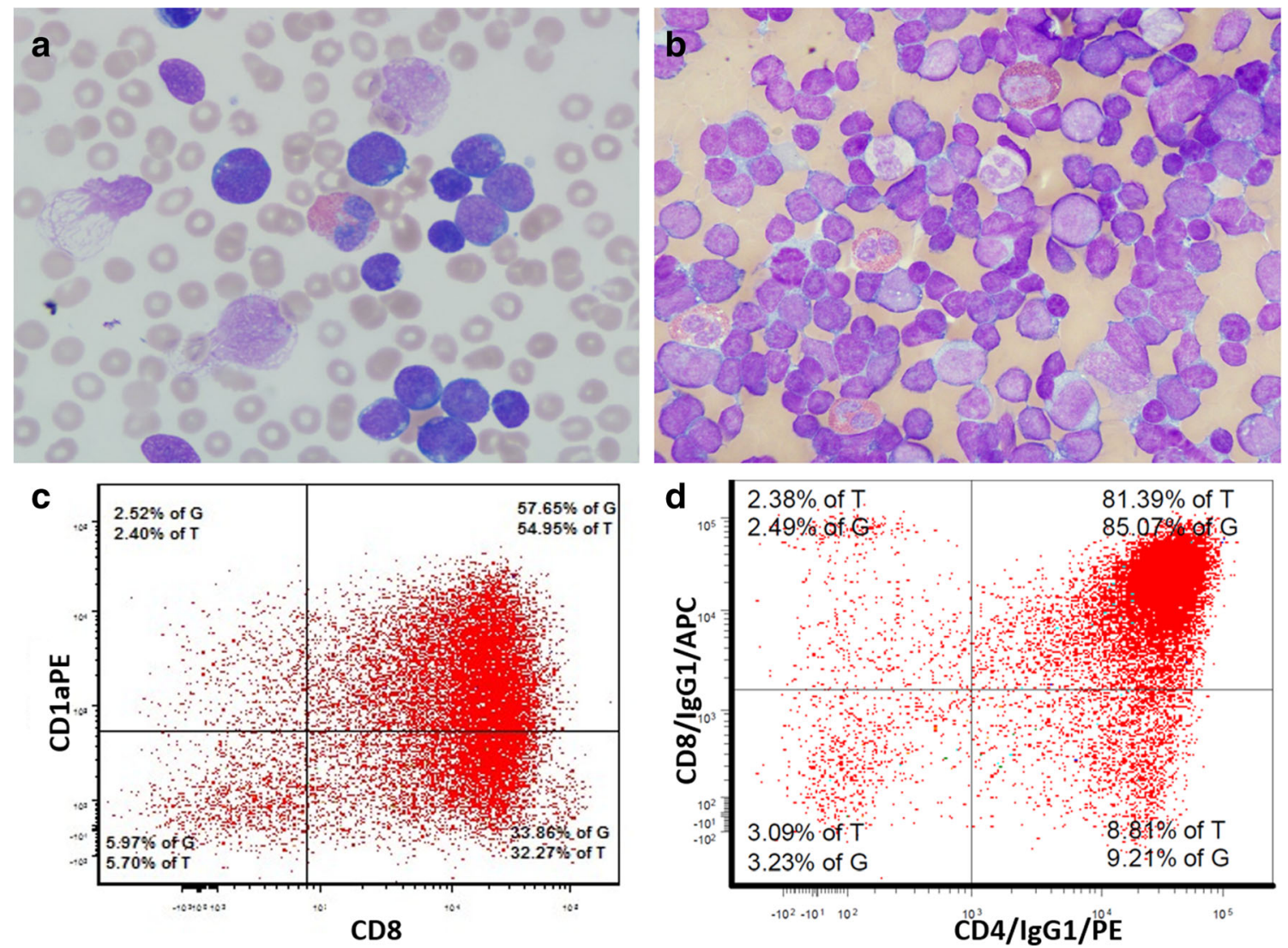

Fig. 1 Peripheral blood smear (A), bone marrow aspirate smear (B), and flow cytometry (C and D). (A and B) Wright stain, $\times 100$ objective; (C and D) flow cytometry on peripheral blood, dot plot CD1a vs CD8 (C) and CD8 vs CD4 (D); blasts are positive for CD4, CD8, and CD1a (60\%) 
but was negative for $B C R-A B L 1, K M T 2 A(M L L)$, and ETV6$R U N X 1$ gene rearrangements. NGS was performed on peripheral blood and found to have a novel gene fusion (TBL1XR1$J A K 2)$. This TBL1XR1-JAK2 fusion was identified to a sequencing depth of $180 \times$ by RNAseq. Additionally, $F B X W 7$ $R 465 H$ mutation and loss of exons $2-3$ of $C D K N 2 A / B$ were also noted in DNAseq, which are the most common genomic alterations in T-ALL/LBL [3].

The patient was started on induction therapy with cytarabine, vincristine, daunorubicin, and prednisolone. Follow-up bone marrow aspirate on day 28 post-induction revealed no morphologic evidence of residual leukemia. Peripheral blood count improved, with WBC $\left(4 \times 10^{\wedge} 9 / \mathrm{L}\right)$ and platelet count $\left(254 \times 10^{\wedge} 11 / \mathrm{L}\right)$; however, mild anemia $(9.1 \mathrm{~g} / \mathrm{dl})$ persisted. The patient did obtain complete remission after one cycle of induction therapy.

\section{Methods}

Wright stain was used for peripheral blood and bone marrow aspirate smears on Sysmex Automated Hematology Analyzer (Sysmex America, Inc., Lincolnshire, IL), model NX-9000, or manually. All sequencing samples and runs were prepared and completed by FoundationOne Heme, a comprehensive genomic profiling by NGS method by Foundation Medicine (Morrisville, NC, and Cambridge, MA). Flow cytometric analysis and conventional karyotyping with the GTW banding technique and banding resolution at 450 were completed by Integrated Oncology Esoterix Genetic Laboratories (Shelton, CT).

\section{Discussion}

Our case is a typical cortical T cell ALL with a novel gene fusion of TXL1XR1-JAK2 and a concurrent increase of absolute eosinophil count in peripheral blood. It shows some features similar to the myeloid/lymphoid neoplasm with PCM1$J A K 2$, a newly proposed provisional entity with a $J A K 2$ fusion and concurrent eosinophilia in the 2016 WHO. The neoplasms reported in this provisional entity are most often seen in myeloid lineage; in only rare cases has this fusion been described in B-ALL/T-ALL $[10,11]$. Clinical presentation of this provisional entity varies from myeloproliferative disorder to acute leukemia. Any JAK2 fusion gene in T-ALL/

Fig. 2 Conventional karyotype. Representative conventional Karyogram showing translocations $\mathrm{t}(3 ; 9)(\mathrm{q} 26 ; \mathrm{p} 24)$ and $\mathrm{t}(11 ; 14)(\mathrm{p} 13 ; \mathrm{q} 11.2)$ in 7 of 20 metaphase cells examined

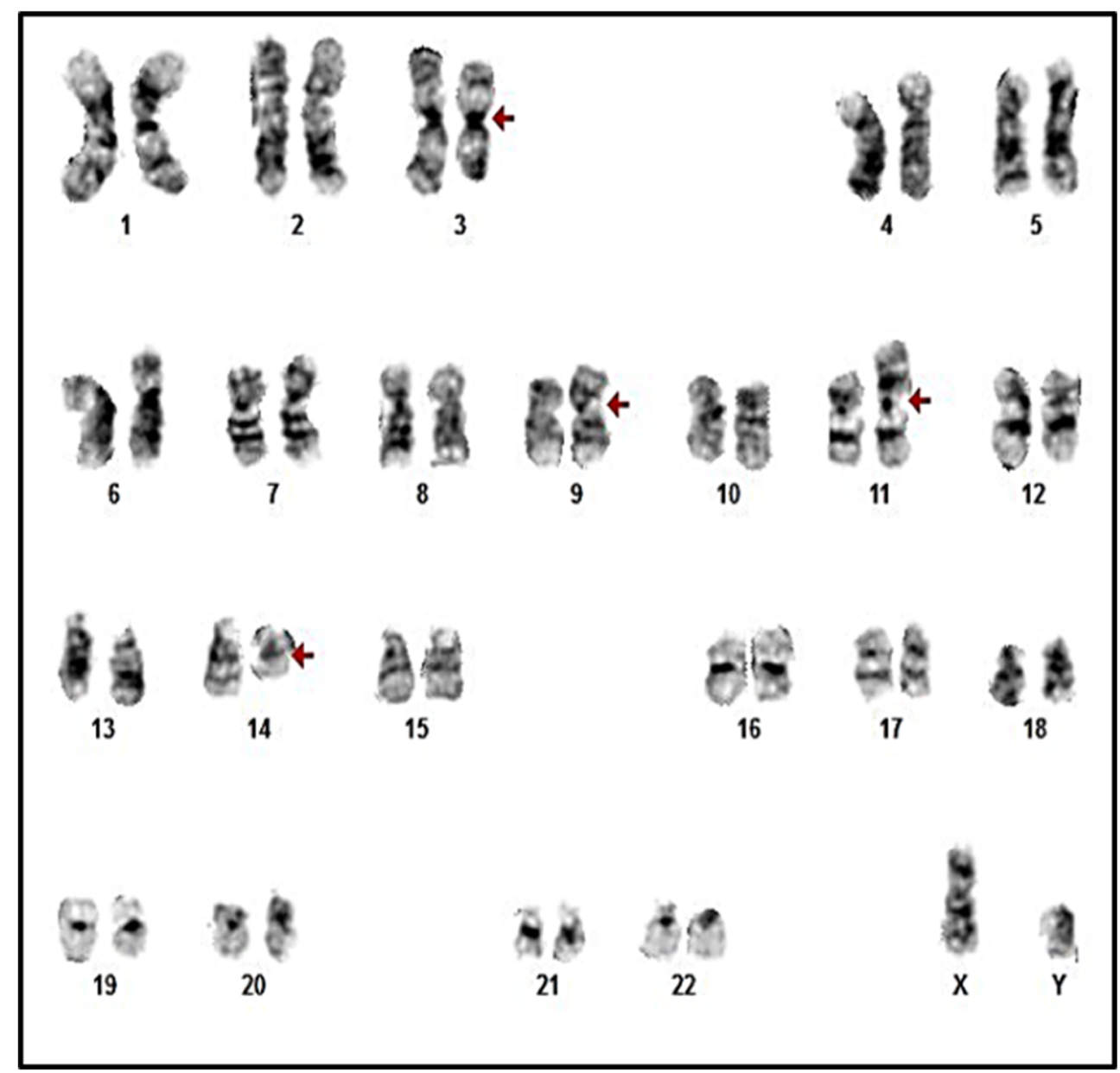


LBL is extremely rare; only six cases have been reported (see Table 1). Its role in prognosis remains unknown.

NGS data identified that the TBL1XR1-JAK2 fusion gene and breakpoints are located at chr3:176750806-176750846 in TBL1XR1 (ENSG00000177565) and chr9:5073715-5073755 in JAK2 (ENSG00000096968) in this patient. TBL1XR1$J A K 2$ gene fusion causes a hybrid protein that combines the $\mathrm{N}$-terminal portion of the TBL1XR1 and kinase portion of $J A K 2$ (Fig. 3). Because the cytogenetic location of the TBL1XR1 gene is $3 \mathrm{q} 26.32$ (https://ghr.nlm.nih.gov/gene/ TBL1XR1), this fusion gene is consistent with the cytogenetic finding of $\mathrm{t}(3 ; 9)(\mathrm{q} 26 ; \mathrm{p} 24)$ translocation. We hypothesize that TBL1XR1-JAK2 gene fusion functions like all other JAK2 chimeric fusions, such as PCM1-JAK2 and TEL-JAK2 [4, 12]. These hybrid proteins cause constitutive activation of the JAK-STAT5 and PI3K signaling pathways, which can regulate cell survival, growth, and differentiation.

TBL1XR1 (transducin-beta-like 1X-related protein 1), also known as TBLR1, is an F-box/WD40-repeat-containing protein that was originally isolated as gene transcript that is preferentially expressed in human $\mathrm{CD} 34^{+} / \mathrm{CD} 38^{-}$earliest human hematopoietic progenitor cells [13]. It is an intrinsic component of the SMRT/NCoR corepressor complexes and is also required for transcriptional activation by nuclear receptors and other regulated transcriptional factors and is also important for the activation of intracellular signaling pathways, such as Wnt/ $\beta$-catenin, $N F-\kappa B$, and Notch [14].

Loss of TBL1XR1 is associated with resistance to glucocorticoids in B-lymphoblastic leukemia (B-ALL) [14]. Recurrent mutations of TBL1XR1 are found in high-risk B-ALL [15]. The TBL1XR1 gene has been reported as a recurrent fusion partner of RARA and $R A R B$ in acute promyelocytic leukemia [16-18] and of TP63 in 5\% of de novo diffuse large B cell lymphoma (DLBCL) of the germinal center B cell-like subtype (GCB) [19]. TBL1XR1-ROS1 in juvenile myelomonocytic leukemia (JMML) and TBL1XR1$P D G F R B$ in acute myeloid leukemia (AML) with eosinophilia are also reported $[20,21]$. The significance of the TBL1XR1 gene alteration in T-ALL/LBL is unknown.

The first case of constitutive activation of JAK2 signaling due to JAK2 fusion with partner TEL (ETVO) in T-ALL/LBL was reported in 1997 [4]. Similarly, a novel ZBTB20-JAK2 fusion was recently reported in a young adult with a newly diagnosed B-ALL with eosinophilia [12]. Our case is a JAK2 fusion with a novel partner TBL1XR1 in a T-ALL/LBL patient with a significant increase in the absolute count of eosinophils. We predict that TBL1XR1-JAK2 may have a similar function as the PCM1-JAK2 fusion gene and could be a new variant in this family. Furthermore, this fusion may potentially be a target of TKI therapy.

In summary, the TBL1XR1-JAK2 gene fusion has not been reported before in the published literature. Its significance in TALL/LBL remains unclear. Additionally, a common chromosome alteration $\mathrm{t}(11 ; 14)(\mathrm{p} 13 ; \mathrm{q} 11.2) / T C R D-L M O 2$ was detected in our patient. This arises from a $\mathrm{T}$ cell receptor delta TCRD $\mathrm{V}(\mathrm{D}) \mathrm{J}$ recombination and leads to $L M O 2$ activation which is suggestive of favorable prognosis [22, 23]. Additional genetic abnormalities are also identified in this case, such as loss of $p 14$ and p16 and mutation of $F B X W 7$, which cause a loss in the control of cell cycle, $c-M y c$, and $P I 3 K$ signaling activation [3]. $J A K 2$ fusions are associated with an aggressive phenotype [24]. Overall, our case is suggestive of a high-risk T-ALL with limited options for therapies. The introduction of TKI may show an improved outcome. Unfortunately, no study on TKI use in lymphoid neoplasms with JAK2 fusion and only a limited number of studies in myeloid neoplasms with PCM1-JAK2 have been reported. Schwaab $J$ and Naumann $N$ group recently reported a study on the treatment of JAK2 fusion-positive myeloid neoplasms (PCM1-JAK2 and BCR-JAK2) in 9 patients using the TKI ruxolitinib [24]. A frequent but transient remission was found in their study. Considering this initial study in a small number of patients, future studies are needed to investigate the potentials of TKI therapeutics in JAK2 fusion-positive myeloid/lymphoid neoplasms.

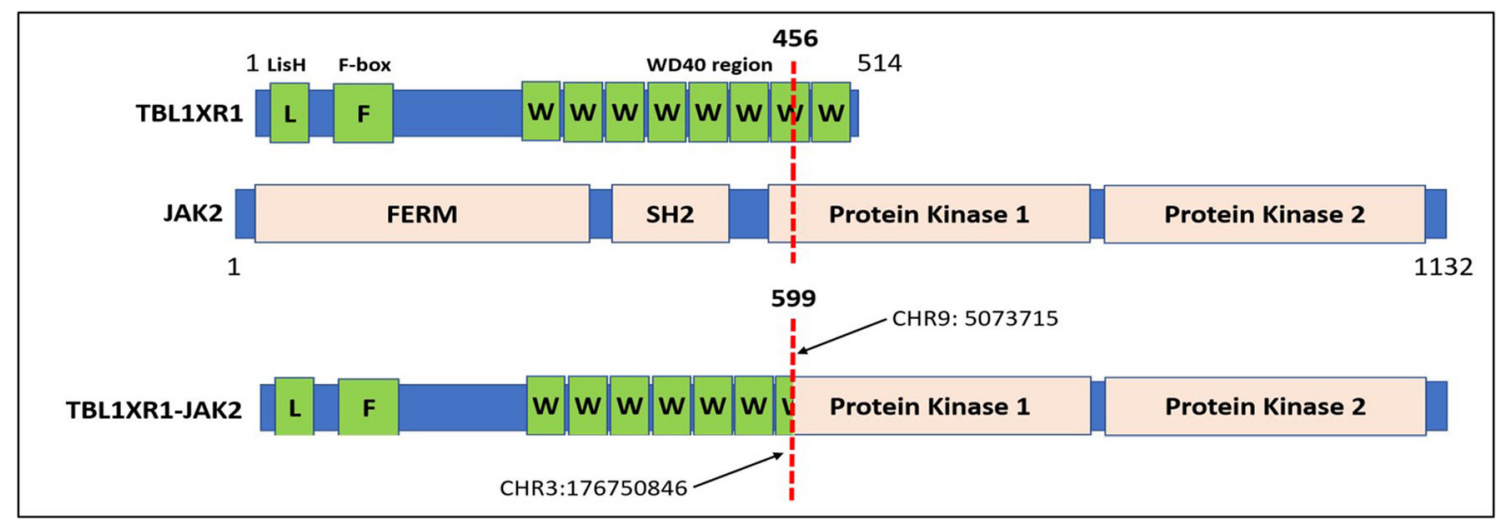

Fig. 3 TBL1XR1-JAK2 chimeric protein structure. TBL1XR1-JAK2 hybrid protein structure demonstrating RNAseq results in a sequencing TBL1XR1 (ENSG00000177565) and chr9:5073715-5073755 in JAK2 (ENSG00000096968) 
Acknowledgments The authors would like to thank Dr. Jenny Libien for her support and financial assistance for the publication. We also appreciate Dr. Janet Schneller, Dr. Susan Gottesman, and Dr. William Fyke for their valuable suggestions and proofreading manuscript.

\section{Compliance with ethical standards}

Conflict of interest The authors declare that they have no conflicts of interest.

\section{References}

1. Pui CH, Relling MV, Downing JR (2004) Acute lymphoblastic leukemia. N Engl J Med 350(15):1535-1548

2. You MJ, Medeiros LJ, Hsi ED (2015) T-lymphoblastic leukemia/ lymphoma. Am J Clin Pathol 144(3):411-422

3. Belver L, Ferrando A (2016) The genetics and mechanisms of T cell acute lymphoblastic leukaemia. Nat Rev Cancer 16(8):494507

4. Lacronique V, Boureux A, Valle VD, Poirel H, Quang CT, Mauchauffé M, Berthou C, Lessard M, Berger R, Ghysdael J, Bernard OA (1997) A TEL-JAK2 fusion protein with constitutive kinase activity in human leukemia. Science. 278(5341):1309-1312

5. Mozziconacci M-J et al (2006) A t $(8 ; 9)$ translocation with PCM1JAK2 fusion in a patient with T-cell lymphoma high incidence of Notch-1 mutations in adult patients with T-cell acute lymphoblastic leukemia. Leukemia. 20(3):536-537

6. Atak ZK, Gianfelici V, Hulselmans G et al (2013) Comprehensive analysis of transcriptome variation uncovers known and novel driver events in T-cell acute lymphoblastic leukemia. PLoS Genet 9(12):e1003997

7. Liu Y, Easton J, Shao Y, Maciaszek J, Wang Z, Wilkinson MR, McCastlain K, Edmonson M, Pounds SB, Shi L, Zhou X, Ma X, Sioson E, Li Y, Rusch M, Gupta P, Pei D, Cheng C, Smith MA, Auvil JG, Gerhard DS, Relling MV, Winick NJ, Carroll AJ, Heerema NA, Raetz E, Devidas M, Willman CL, Harvey RC, Carroll WL, Dunsmore KP, Winter SS, Wood BL, Sorrentino BP, Downing JR, Loh ML, Hunger SP, Zhang J, Mullighan CG (2017) The genomic landscape of pediatric and young adult T-lineage acute lymphoblastic leukemia. Nat Genet 49(8):1211-1218

8. Chen B, Jiang L, Zhong ML, Li JF, Li BS, Peng LJ, Dai YT, Cui BW, Yan TQ, Zhang WN, Weng XQ, Xie YY, Lu J, Ren RB, Chen SN, Hu JD, Wu DP, Chen Z, Tang JY, Huang JY, Mi JQ, Chen SJ (2018) Identification of fusion genes and characterization of transcriptome features in T-cell acute lymphoblastic leukemia. Proc Natl Acad Sci USA 115(2):373-378

9. Strehl S (2006) JAK2 (Janus kinase 2) Atlas Genet Cytogenet Oncol Haematol. 10(1):3-6. (http://AtlasGeneticsOncology.org/ Genes/JAKID98.html). Last visit on 6/7/2020

10. Bain BJ, Ahmad S (2014) Should myeloid and lymphoid neoplasms with PCM1-JAK2 and other rearrangements of JAK2 be recognized as specific entities? Br J Haematol 166(6):809-817

11. Arber DA, Orazi A, Hasserjian R, Thiele J, Borowitz MJ, le Beau MM, Bloomfield CD, Cazzola M, Vardiman JW (2016) The 2016 revision to the World Health Organization classification of myeloid neoplasms and acute leukemia. Blood. 127(20):2391-2405

12. Peterson JF, Blackburn PR, Webley MR, Pearce KE, Williamson CM, Vasmatzis G, Smadbeck JB, Bieliauskas SL, Reichard KK, Ketterling RP, Baughn LB, Greipp PT (2019) Identification of a novel ZBTB20-JAK2 fusion by mate-pair sequencing in a young adult with B-lymphoblastic leukemia/lymphoma. Mayo Clin Proc 94(7):1381-1384
13. Zhang X, Dormady SP, Basch RS (2000) Identification of four human cDNAs that are differentially expressed by early hematopoietic progenitors. Exp Hematol 28(11):1286-1296

14. Li JY, Daniels G, Wang J, Zhang X (2015) TBL1XR1 in physiological and pathological states. Am J Clin Exp Urol 3(1):13-23

15. Zhang J, Mullighan CG, Harvey RC, Wu G, Chen X, Edmonson M, Buetow KH, Carroll WL, Chen IM, Devidas M, Gerhard DS, Loh ML, Reaman GH, Relling MV, Camitta BM, Bowman WP, Smith MA, Willman CL, Downing JR, Hunger SP (2011) Key pathways are frequently mutated in high-risk childhood acute lymphoblastic leukemia: a report from the Children's Oncology Group. Blood. 118(11):3080-3087

16. Chen Y, Li S, Zhou C, Li C, Ru K, Rao Q, Xing H, Tian Z, Tang K, Mi Y, Wang B, Wang M, Wang J (2014) TBLR1 fuses to retinoid acid receptor $\alpha$ in a variant $\mathrm{t}(3 ; 17)(\mathrm{q} 26 ; \mathrm{q} 21)$ translocation of acute promyelocytic leukemia. Blood. 124(6):936-945

17. Osumi T, Watanabe A, Okamura K, Nakabayashi K, Yoshida M, Tsujimoto SI, Uchiyama M, Takahashi H, Tomizawa D, Hata K, Kiyokawa N, Kato M (2019) Acute promyelocytic leukemia with a cryptic insertion of RARA into TBL1XR1. Genes Chromosomes Cancer 58(11):820-823

18. Osumi T, Tsujimoto SI, Tamura M, Uchiyama M, Nakabayashi K, Okamura K, Yoshida M, Tomizawa D, Watanabe A, Takahashi H, Hori T, Yamamoto S, Hamamoto K, Migita M, Ogata-Kawata H, Uchiyama T, Kizawa H, Ueno-Yokohata H, Shirai R, Seki M, Ohki K, Takita J, Inukai T, Ogawa S, Kitamura T, Matsumoto K, Hata K, Kiyokawa N, Goyama S, Kato M (2018) Recurrent RARB translocations in acute promyelocytic leukemia lacking $R A R A$ translocation. Cancer Res 78(16):4452-4458

19. Scott DW, Mungall KL, Ben-Neriah S, Rogic S, Morin RD, Slack GW, Tan KL, Chan FC, Lim RS, Connors JM, Marra MA, Mungall AJ, Steidl C, Gascoyne RD (2012) TBL1XR1/TP63: a novel recurrent gene fusion in B-cell non-Hodgkin lymphoma. Blood. 119(21): 4949-4952

20. Murakami N, Okuno Y, Yoshida K, Shiraishi Y, Nagae G, Suzuki K, Narita A, Sakaguchi H, Kawashima N, Wang X, Xu Y, Chiba K, Tanaka H, Hama A, Sanada M, Ito M, Hirayama M, Watanabe A, Ueno T, Kojima S, Aburatani H, Mano H, Miyano S, Ogawa S, Takahashi Y, Muramatsu H (2018) Integrated molecular profiling of juvenile myelomonocytic leukemia. Blood. 131(14):1576-1586

21. Campregher PV, Halley NDS, Vieira GA et al (2017) Identification of a novel fusion TBL1XR1-PDGFRB in a patient with acute myeloid leukemia harboring the DEK-NUP214 fusion and clinical response to dasatinib. Leuk Lymphoma 58(12):2969-2972

22. Dik WA, Nadel B, Przybylski GK, Asnafi V, Grabarczyk P, Navarro JM, Verhaaf B, Schmidt CA, Macintyre EA, van Dongen JJM, Langerak AW (2007) Different chromosomal breakpoints impact the level of LMO2 expression in T-ALL. Blood. 110(1):388-392

23. Hunger SP, Mullighan CG (2015) Redefining ALL classification: toward detecting high-risk ALL and implementing precision medicine. Blood. 125(26):3977-3987

24. Schwaab J, Naumann N, Luebke J, Jawhar M, Somervaille TCP, Williams MS, Frewin R, Jost PJ, Lichtenegger FS, la Rosée P, Storch N, Haferlach T, Horny HP, Fabarius A, Haferlach C, Burchert A, Hofmann WK, Cross NCP, Hochhaus A, Reiter A, Metzgeroth G (2020) Response to tyrosine kinase inhibitors in myeloid neoplasms associated with PCM1-JAK2, BCR-JAK2 and ETV6-ABL1 fusion genes. Am J Hematol 95(7):824-833

Publisher's note Springer Nature remains neutral with regard to jurisdictional claims in published maps and institutional affiliations. 